\title{
Construction and comparison of fluorescence and bioluminescence bacterial biosensors for the detection of bioavailable toluene and related compounds
}

\author{
Yueh-Fen $\mathrm{Li}^{\mathrm{a}}$, Feng-Yin $\mathrm{Li}^{\mathrm{b}}$, Chen-Lung $\mathrm{Ho}^{\mathrm{c}}$, Vivian Hsiu-Chuan Liao ${ }^{\mathrm{a}, *}$ \\ ${ }^{a}$ Department of Bioenvironmental Systems Engineering, National Taiwan University, 1 Roosevelt Road, Sec. 4, Taipei 106, Taiwan \\ ${ }^{\mathrm{b}}$ Department of Chemistry, National Chung Hsing University, 250 Kuo Kuang Road, Taichung 402, Taiwan \\ ${ }^{\mathrm{c}}$ Division of Wood Cellulose, Taiwan Forestry Research Institute, 53 Nanhai Road, Taipei 100, Taiwan
}

Received 22 February 2007; received in revised form 16 April 2007; accepted 3 May 2007

The choice of reporter genes for toluene bacterial biosensors to determine BTEX bioavailability is case-specific.

\begin{abstract}
Environmental pollution with petroleum products such as benzene, toluene, ethylbenzene, and xylenes (BTEX) has garnered increasing awareness because of its serious consequences for human health and the environment. We have constructed toluene bacterial biosensors comprised of two reporter genes, $g f p$ and $\operatorname{lu} x C D A B E$, characterized by green fluorescence and luminescence, respectively, and compared their abilities to detect bioavailable toluene and related compounds. The bacterial luminescence biosensor allowed faster and more-sensitive detection of toluene; the fluorescence biosensor strain was much more stable and thus more applicable for long-term exposure. Both luminescence and fluorescence biosensors were field-tested to measure the relative bioavailability of BTEX in contaminated groundwater and soil samples. The estimated BTEX concentrations determined by the luminescence and fluorescence bacterial biosensors were closely comparable to each other. Our results demonstrate that both bacterial luminescence and fluorescence biosensors are useful in determining the presence and the bioavailable fractions of BTEX in the environment.
\end{abstract}

(C) 2007 Elsevier Ltd. All rights reserved.

Keywords: BTEX; Luminescence; Fluorescence; Bacterial biosensors; Bioavailability

\section{Introduction}

Environmental pollution with petroleum products has garnered increasing awareness because of its serious consequences for human health and the environment. Of particular concern for drinking water quality is the more-water-soluble aromatic components, such as benzene, toluene, ethylbenzene, and xylenes (BTEX) from petroleum products. The detection of these compounds is thus of paramount importance to public and government agencies responsible for monitoring and

\footnotetext{
* Corresponding author. Tel.: +88623366 5239; fax: +886233663462. E-mail address: vivianliao@ntu.edu.tw (V.H.-C. Liao).
}

cleaning up contaminated sites. Therefore, it is necessary to develop sensitive, reliable, effective, and inexpensive methods which can efficiently determine the presence and amounts of hazardous aromatic compounds in the environment so that they can be monitored. Traditionally, the environmental risks caused by pollution of aromatic compounds were determined using conventional analytical methods such as high-performance liquid chromatography (HPLC) or gas chromatography-mass spectrometry (GC-MS). However, chemical methods are not able to distinguish between available (potentially hazardous) and non-available (potentially non-hazardous) fractions of organic compounds to biological systems. This is of particular interest with respect to solid environments, e.g., soils, because of the great adsorption capability of organic compounds to 
solid phases. Moreover, the main drawback of chemical methods is the question of the transfer of results obtained from abiotic systems to biological ones.

Recent advances in bacterial-based biosensors with inducible reporter genes allowed their expanded application to environmental monitoring purposes to assess the bioavailability of specific pollutants in complex environments. A number of strains have been designed to detect organic contaminants (Applegate et al., 1998; Willardson et al., 1998; Stiner and Halverson, 2002). Such strains typically combine a promoter-operator, which acts as the sensing element, with one or more reporter genes coded for easily detectable proteins. Commonly used reporter genes include lacZ, gfp, lucFF, $\operatorname{lu} x A B$, and luxCDABE. Among these, use of the entire lux $C D A B E$ gene cassette has been extensive because such a reporter does not require the addition of an exogenous substrate for signal production. Unlike luciferase, $\beta$-galactosidase, and similar enzyme-based reporter systems, a fluorescent protein, such as the green fluorescent protein (GFP), is detected by its presence and not by its activity, and it requires no exogenous substrates or cofactor for signal production. Although different reporter genes have been widely studied, few studies have examined differences in reporter genes in whole-cell sensor bacteria. Moreover, in most studies, growth conditions or genetic constructs were not identical, which makes direct comparison of the reporters impossible (Hansen and Sørensen, 2000; Sagi et al., 2003).

In this report, we engineered toluene bacterial biosensors comprised of two reporter genes, gfp and luxCDABE, which are respectively characterized by green fluorescence and luminescence, for the detection of bioavailable toluene and related compounds, and characterized their sensitivities and specificities to the target compounds. This bacterial biosensor is based on a plasmid incorporating the transcriptional activator, $x y l R$, from the TOL plasmid carried by the toluene-degrading soil microbe, Pseudomonas putida mt-2 (Burlage et al., 1989). The XylR protein binds to toluene and related compounds and activates transcription at its promoter, $\mathrm{Pu}$. A reporter plasmid was constructed by inserting the reporter gene under the control of toluene-responsive regulatory units (XylR and $\mathrm{Pu}$ ). Cells harboring this construct detected toluene and its related compounds with high sensitivity. We compared the performance of the bacterial luciferase operon (Vibrio fischeri luxCDABE) and the jellyfish GFP (Aequorea victoria gfp) in identical constructs. Moreover, the use of both bacterial biosensors to measure bioavailable fractions of BTEX in contaminated environmental samples was described. The results obtained in this report should help in selecting the most suitable reporter genes for use in whole-cell bacterial sensors to analyze the bioavailability of pollutants in the environment.

\section{Materials and methods}

\subsection{Chemicals}

Unless otherwise stated, all chemicals used were analytical reagent grade or better and were purchased from Sigma-Aldrich (St. Louis, MO, USA).
All media and buffer solutions were prepared using deionized distilled water (Barnstead, Dubuque, IA, USA). Restriction endonucleases and T4 DNA ligase were supplied from New England Biolabs (Beverly, MA, USA) The DNA polymerase used in the polymerase chain reaction (PCR) was from Qiagen (Hilden, Germany).

\subsection{Construction of the biosensor plasmid}

The toluene biosensor plasmid was constructed by transcriptional fusion. For plasmid containing $g f p$ as the reporter gene, the Pu promoter was amplified from DNA purified from $P$. putida mt-2 by PCR using the forward primer $5^{\prime}$ CCGGAATTCGGAAAGCGCGATGAAC- $3^{\prime}$, containing an EcoRI site, and a reverse primer, 5'-CGCGGATCCGACTCCAGGCGTAACG-3', containing a BamHI site. Subsequently the Pu promoter sequence was inserted into the EcoRI and BamHI sites of the promoterless pPROBE-NT' vector (Miller et al., 2000). The $x y l R$ gene, including its promoter (Pr), was also PCR-amplified using the forward primer $5^{\prime}$-CCGACCGGTATTTTAATGTGGGCT GCTTGGT- $3^{\prime}$ and the reverse primer 5'-CGCACCGGTTTTTCACACAACC TGGGGCG- $3^{\prime}$, both of which contain an AgeI site. The $x y l R$ amplicon and the plasmid with the $\mathrm{Pu}$ insert were digested with AgeI, after which the two were ligated together and then transformed into Escherichia coli DH5 $\alpha$ cells to produce the final pTOLGFP plasmid construct (see Fig. 1A).

For the plasmid containing luxCDABE as the reporter gene, the recombinant plasmid pTOLLUX (Fig. 1B), was constructed analogously to that of pTOLGFP except for the following: the Pu promoter sequence was inserted

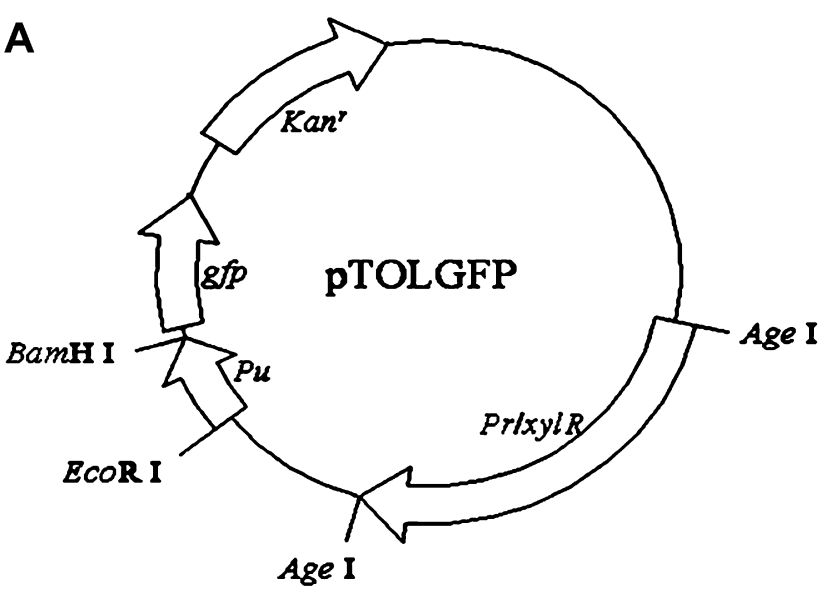

B

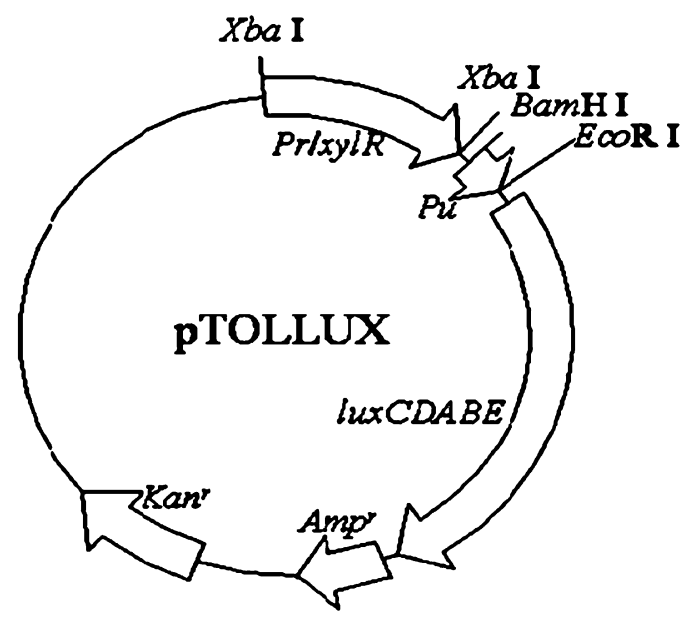

Fig. 1. Schematic organization of the biosensor plasmids. Abbreviations: $\operatorname{kan}^{\mathrm{r}}$, gene encoding kanamycin resistance; $\mathrm{Amp}^{\mathrm{r}}$, gene encoding ampicillin resistance; $g f p$, green fluorescent protein gene; luxCDABE, genes of bacterial luciferase operon. The diagram is not drawn to scale. 
into the EcoRI and BamHI sites of the promoterless pUCD615 vector (Rogowsky et al., 1987) and the $x y l R$ amplicon was PCR-amplified with primers containing an XbaI site.

\subsection{Bacterial growth and assay conditions}

E. coli DH5 $\alpha$ cells harboring pTOLGFP or pTOLLUX were grown in Luria-Bertani (LB) broth, in the presence of either kanamycin $\left(50 \mu \mathrm{g} \mathrm{ml}^{-1}\right)$ or ampicillin $\left(100 \mu \mathrm{g} \mathrm{ml}^{-1}\right)$ to ensure plasmid maintenance. Overnight cultures were diluted 100-fold into fresh medium supplemented with kanamycin or ampicillin and incubated at $37{ }^{\circ} \mathrm{C}$ in an orbital shaker at $225 \mathrm{rpm}$ until the optical density at $600 \mathrm{~nm}\left(\mathrm{OD}_{600}\right)$ reached 0.6 . The cultures were then added to 180 $\mu \mathrm{l}$ aliquots in tetraplicate wells of a 96-well plate (Thermo Labsystems, Helsinki, Finland), already containing $20 \mu \mathrm{l}$ of the appropriate concentration of the tested inducer in LB. The plates were then placed in a temperature-controlled microtiter plate luminometer/fluorometer (Thermo Labsystems, Helsinki, Finland), and the luminescence/fluorescence was measured at intervals for the duration of the experiment. Viable cell numbers (colony forming unit, $\mathrm{CFU}$ ) and the luminescence and fluorescence intensities produced by the bacteria were also measured. For fluorescence measurements, GFP was excited at $485 \mathrm{~nm}$ and measured at $535 \mathrm{~nm}$. Raw fluorescence and bioluminescence intensities were expressed in the instrument's arbitrary relative units (RFU or RLU, respectively). The specific fluorescence intensity (SFI) and specific bioluminescence intensity (SLI) are defined as RFU or RLU, respectively, divided by the viable cell numbers (CFU) measured at each concentration and time point. Induction ratios (IRs) were calculated using the formula IR $=L_{\mathrm{i}} / L_{\mathrm{b}}$; where $\mathrm{Li}$ is the fluorescence (in SFI) or luminescence (in SLI) value of the sample, and $L_{\mathrm{b}}$ is the fluorescence (in SFI) or luminescence (in SLI) value of cells in a solution containing no inducer (blank). All experiments were carried out with four replicates and were repeated at least three times. Variations among the four replicates and between different experiments did not exceed $5 \%$ and $15 \%$, respectively.

\subsection{Selectivity studies}

Induction of the sensing system by various aromatic compounds, including toluene, naphthalene, $o$-xylene, $p$-xylene, catechol, ethylbenzene, phenol, acetophenone, and benzaldehyde, was studied by measuring the fluorescence and luminescence produced. Each aromatic compound was dissolved in ethanol and added to media containing the bacterial sensor culture at a final concentration of $1 \mathrm{mmol} \mathrm{L}^{-1}$. Cells were incubated for $2 \mathrm{~h}$ at $37^{\circ} \mathrm{C}$, and then the SFI and SLI were measured as described above. At least three independent experiments were performed for each kind of organic compound.

\subsection{Testing of contaminated soil samples with the bacterial biosensors}

Contaminated groundwater and soil samples were obtained from Lin-Yuan Industrial Park, Kaohsiung, Taiwan in December 2005. Contaminated soil samples were extracted with deionized water. The soil-water extract was prepared by mixing air-dried soil with deionized water using a soil-water ratio of 1:9 (w/v) (Layton et al., 1994; Flynn et al., 2003). Subsequently, the suspensions were shaken at room temperature for $24 \mathrm{~h}$, followed by centrifugation at $13,000 \times g$ for $10 \mathrm{~min}$, and then the supernatants were used for chemical and biosensor analyses.

For chemical analysis, concentrations of toluene in groundwater and in water extracts of soil samples were determined by GC-MS (Hewlett-Packard HP6890/HP5973, Palo Alto, CA, USA). For the biosensor analysis, $250 \mu \mathrm{l}$ of groundwater or soil water extract was added to $250 \mu$ of $6 \times$ concentrated LB medium, $265 \mu \mathrm{l}$ of deionized distilled water, and $735 \mu \mathrm{l}$ of $E$. coli DH5 $\alpha$ cells harboring pTOLGFP or pTOLLUX in LB medium at a cell density of $0.6 \mathrm{OD}_{600}$. Cells were incubated for $2 \mathrm{~h}$ at $37^{\circ} \mathrm{C}$, and then SFI and SLI for the GFP-based biosensor and LUX-based biosensor, respectively, were measured using the procedures described above. Samples containing known concentrations of toluene were tested in parallel with $250 \mu \mathrm{l}$ of deionized distilled laboratory water in place of environmental samples to generate a standard curve. A standard curve was derived from a linear regression of the average SFI or SLI values at each particular toluene concentration, and then the concentrations of toluene equivalents in the environmental samples were calculated from the standard curve. In order to examine possible inhibitory effects on fluorescence and luminescence resulting from chemicals in addition to the effector compounds in the environmental samples, $500 \mu \mathrm{mol} \mathrm{L}^{-1}$ of toluene was added to the environmental samples, and the fluorescence and luminescence were compared to those of a positive control containing the same concentration of toluene in deionized water.

\subsection{Data analysis}

The experiments were performed at least three times for error analyses. The data were used to calculate the standard deviations, represented by error bars in the figures. Student's $t$-test analysis at the $\alpha=0.05$ level was used to check the results for significance. Standard curves were fitted by a linear regression analysis.

\section{Results}

\subsection{Description of the bacterial biosensors}

The toluene bacterial biosensors comprised of two reporter genes, $g f p$ and luxCDABE, and characterized by green fluorescence and luminescence, respectively, were compared in the present study. We compared the expressions of these two reporters by fusing their genes to a single promoter, $\mathrm{Pu}$, and exposing the constructs to toluene. The Pu promoter and $\operatorname{Pr} / x y l R$ genes of $P$. putida TOL plasmid were cloned into the promoterless vector, $\mathrm{pPROBE}-\mathrm{NT}^{\prime}$, which contains the $g f p$ gene (Miller et al., 2000) and pUCD615 which contains the lux$C D A B E$ gene (Rogowsky et al., 1987), respectively. The two constructed toluene biosensor plasmids were designated pTOLGFP and pTOLLUX, respectively, as shown in Fig. 1. When E. coli DH5 $\alpha$ cells were transformed with the pTOLGFP recombinant plasmid, GFP fluorescence was observed in response to toluene resulting in a statistically significant increase in the fluorescence intensity relative to that of cells with no-toluene control. Similarly, E. coli DH5 $\alpha$ cells harboring the pTOLLUX plasmid showed a statistically significant increase in the luminescence intensity relative to that of cells with no-toluene control.

The responses of the fluorescence and luminescence bacterial biosensors to various aromatic compounds were further evaluated. Both E. coli DH5 $\alpha$ (pTOLGFP) and E. coli DH5 $\alpha$ (pTOLLUX) cells were treated with $1.0 \mathrm{mmol} \mathrm{L}^{-1}$ of various aromatic compounds for $2 \mathrm{~h}$ prior to the green fluorescence and luminescence measurements, as described in Section 2. The levels of fluorescence and luminescence of the biosensing systems subjected to organic compounds are plotted in Fig. 2. The responses to each compound by both biosensors were similar. However, the bioluminescent sensor strain appeared to be more sensitive to the effectors. For $2 \mathrm{~h}$ of exposure to cells harboring pTOLLUX, a significant increase in the luminescence was observed for toluene, naphthalene, $o$-xylene, $p$-xylene, catechol, ethylbenzene, phenol, and benzaldehyde. No statistically significant change in the luminescence was observed for acetophenone. In contrast, neither acetophenone, catechol, phenol, nor benzaldehyde caused a statistically significant change in the green fluorescence compared to the control. 


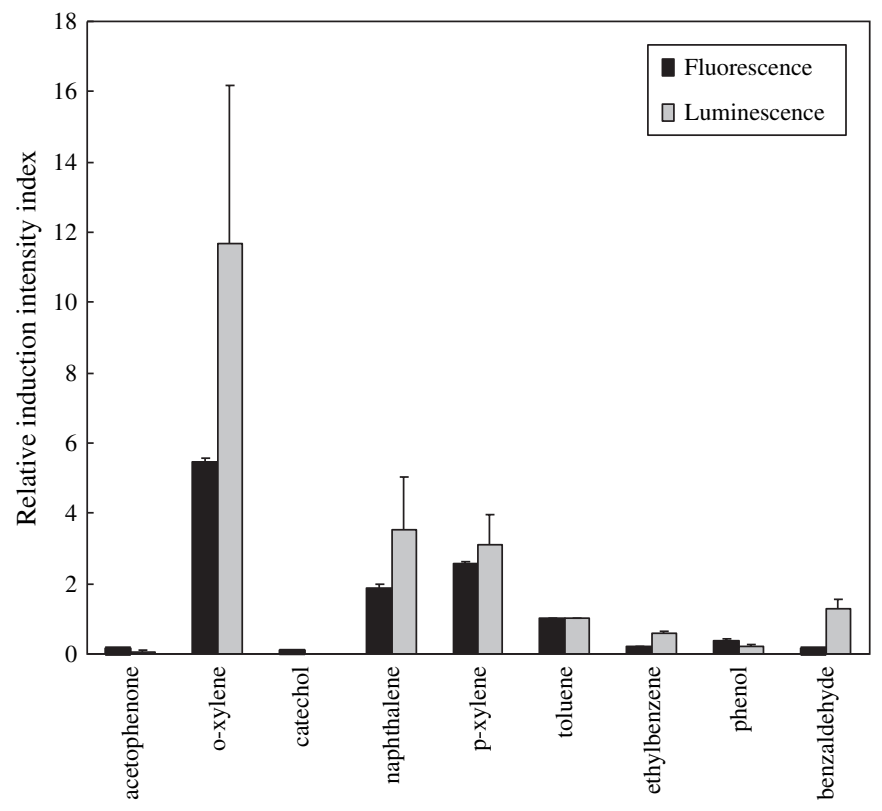

Fig. 2. Comparison of the responses of the green fluorescence and luminescence biosensors to aromatic compounds. E. coli DH5 $\alpha$ (pTOLGFP) and E. coli $\mathrm{DH} 5 \alpha$ (pTOLLUX) were treated with $1 \mathrm{mmol} \mathrm{L}^{-1}$ of various aromatic compounds for $2 \mathrm{~h}$. Relative induction intensity index is defined as the induction intensity of each chemical divided by the induction intensity of toluene. The induction intensity is defined as the value of the culture-specific fluorescence/luminescence intensities (in SFI/SLI) with chemical treatment minus the culture-specific fluorescence/luminescence intensities (in SFI/SLI) of the control divided by the culture-specific fluorescence/luminescence intensities (in SFI/SLI) of the control. Specific fluorescence/luminescence intensities (in $\mathrm{SFI} / \mathrm{SLI}$ ) were measured as described in Section 2. Control refers to the biosensor bacteria without chemical treatment. The data presented here are the mean values of at least three independent experiments with standard deviations.

This might have been due to the lower sensitivity of the GFPbased biosensor since significant increases in the green florescence were observed for catechol, phenol, and benzaldehyde after $3 \mathrm{~h}$ of exposure (data not shown).

\subsection{Comparison of the time-dependent induction of the green fluorescence and luminescence biosensors with toluene}

The time-dependent induction of the bacterial sensors in response to toluene was determined by incubating the cells with toluene for various time intervals as described in Section 2. Neither the background fluorescence nor luminescence exhibited by the untreated biosensors exhibited any statistically significant change during the incubation period (data not shown). As shown in Fig. 3, the induction of fluorescence and luminescence by toluene occurred in a time-dependent manner. For $E$. coli DH5 $\alpha$ (pTOLGFP) cells, as the time of induction by toluene increased, there was an increase in the green fluorescence emitted by the bacterial cells during the first $5 \mathrm{~h}$ of the incubation period (Fig. $3 \mathrm{~A}$ ). In contrast, $E$. coli DH5 $\alpha$ (pTOLLUX) cells showed a different kinetic profile. The specific luminescence intensity continuously
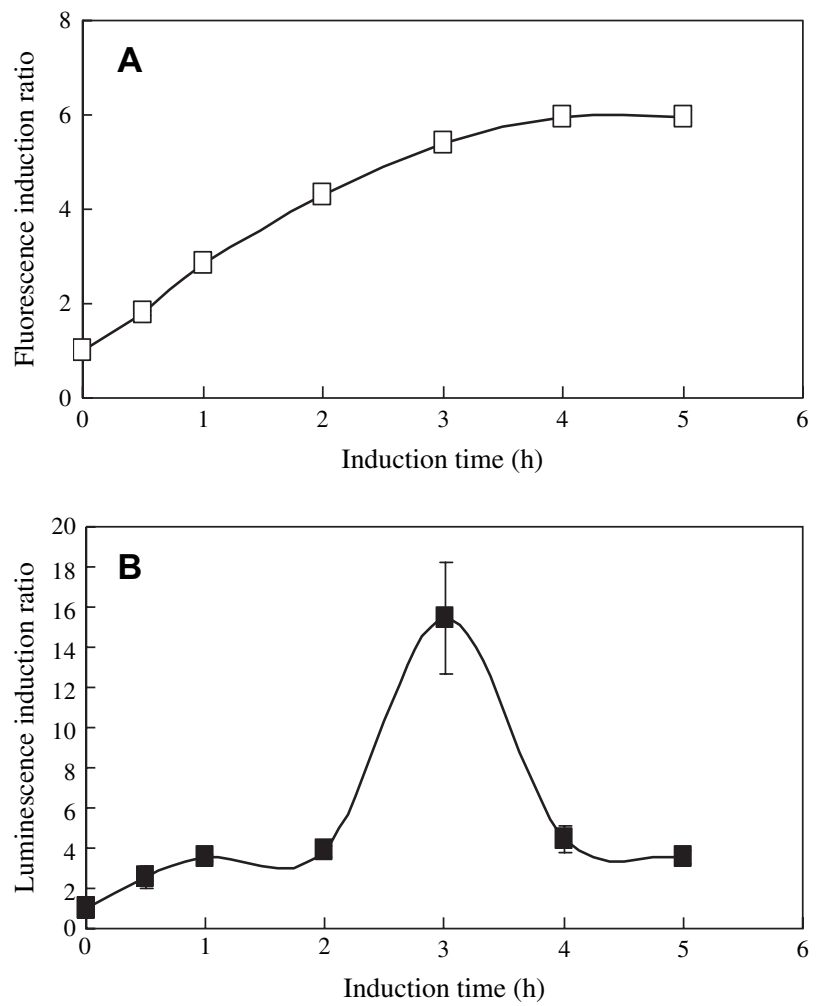

Fig. 3. Comparison of the time-dependent induction of the green fluorescence and luminescence biosensors with toluene. E. coli DH5 $\alpha$ (pTOLGFP) and E. coli DH5 $\alpha$ (pTOLLUX) were exposed to $750 \mu \mathrm{mol} \mathrm{L}^{-1}$ toluene, and the specific fluorescence intensity (in SFI) and specific luminescence intensity (in SLI) for E. coli DH5 $\alpha$ (pTOLGFP) and E. coli DH5 $\alpha$ (pTOLLUX), respectively, were determined after different exposure periods as described in Section 2. (A) For the fluorescence biosensor, the induction ratio is the SFI of the toluene-exposed sample divided by the SFI of a no-toluene control; and (B) For the luminescence biosensor, the induction ratio is the SLI of a toluene-exposed sample divided by the SLI of a no-toluene control; the no-toluene control was arbitrarily set to 1.0. The data presented here are the mean values of at least three independent experiments with standard deviations.

increased from the background value during the first $3 \mathrm{~h}$ of incubation, after which the luminescence began to dramatically decrease (Fig. 3B). This might have been due to the biochemical nature of the lux reporter gene (Hakkila et al., 2002; Dollard and Billard, 2003). Additionally, there is an apparent difference between the two reporters in the lag time prior to a significant increase ( $\geq 2$-fold) in the signal above the background: approximately $60 \mathrm{~min}$ for GFP and only $30 \mathrm{~min}$ for the Lux reporter. Clearly, the catalytic nature of the bioluminescent reporter system allows the more-rapid accumulation of signals. Moreover, it may also be observed that the signal intensity of Lux was higher than that of GFP. This may have been the reason for the earlier detection by the Lux reporter. It should be noted, however, that an increase in sensitivity for the fluorescence biosensor can be achieved by prolonging the exposure periods. Therefore, when fluorescent data were collected for $4 \mathrm{~h}$ or more, the detection sensitivity of the fluorescent signal surpassed that of the bioluminescent one; while the latter peaked after approximately $3 \mathrm{~h}$ and then decreased, the fluorescent signal continued to accumulate for $7 \sim 8 \mathrm{~h}$ and then remained stable (data not shown). 
3.3. Comparison of the dose-dependent induction of the green fluorescence and luminescence biosensors with toluene

Further differences between these two toluene biosensors can be observed in Fig. 4, which compares the responses of the GFP-based and Lux-based biosensors. For assay development and comparison purposes, a 2-h induction period was chosen to plot the dose-response curves, since the green fluorescence and luminescence signals obtained during this time period were sufficiently high. Both the green fluorescence and luminescence intensities increased with the concentration of toluene to a certain level. At concentrations lower than the detection limit of toluene, binding of XylR to the Pu promoter sequence repressed transcription and translation of the reporter gene. The addition of toluene de-repressed expression of the reporter gene.

The dose-response curves for the fluorescent and bioluminescent sensors were similar. However, the bioluminescent sensor strain appeared to be more sensitive to toluene, and displayed a dose-dependent response at toluene concentrations of
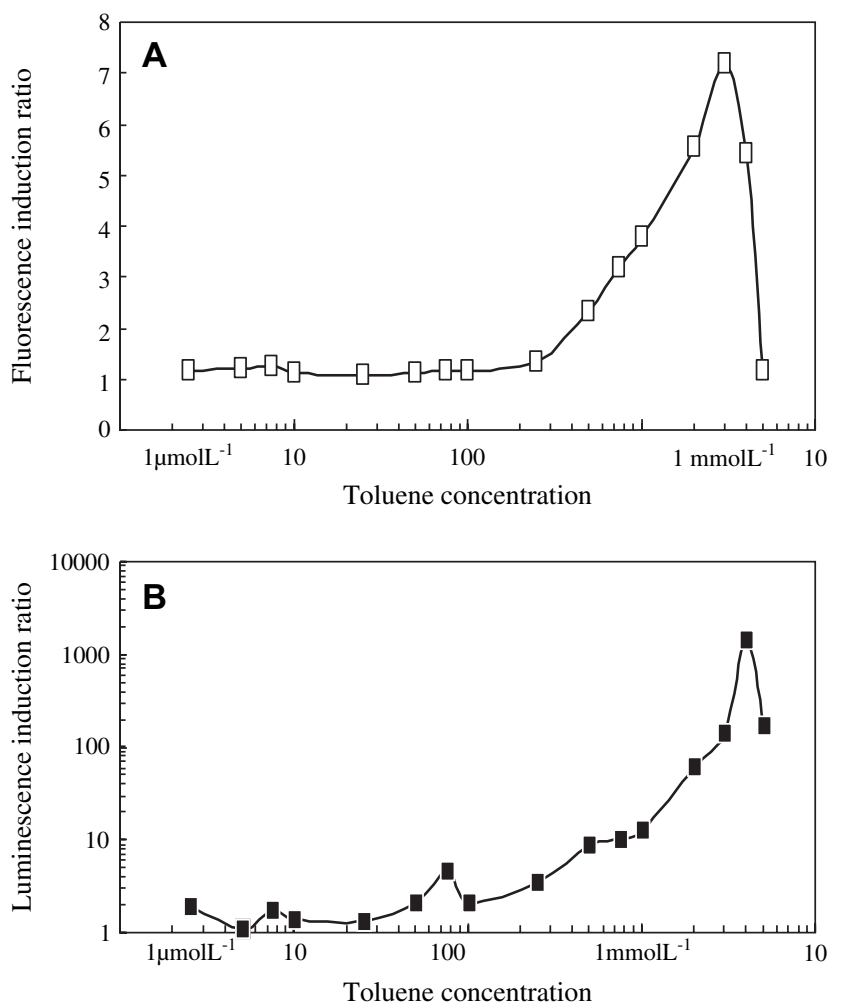

Fig. 4. Comparison of the dose-dependent induction of the green fluorescence and luminescence biosensors by toluene. Fluorescence and luminescence from E. coli DH5 $\alpha$ cells harboring the pTOLGFP and pTOLLUX plasmids were determined after 2-h incubations with various concentrations of toluene, as described in Section 2. (A) For the fluorescence biosensor, the induction ratio is the specific luminescence intensity (SFI) of the toluene-exposed sample divided by the SFI of a no-toluene control; and (B) For the luminescence biosensor, the induction ratio is the SLI of the toluene-exposed sample divided by the SLI of a no-toluene control; the no-toluene control was arbitrarily set to 1.0 . The data presented here are the mean values of at least three independent experiments with standard deviations. The standard deviation is smaller than the symbol used in the figure. as low as $7.5 \mu \mathrm{mol} \mathrm{L}^{-1}$. In contrast, the detection threshold for the fluorescent biosensor was $25 \mu \mathrm{mol} \mathrm{L}^{-1}$.

\subsection{Comparison of tests of contaminated groundwater and soil with the green fluorescence and luminescence biosensors}

To demonstrate the utility of the toluene biosensors for measuring actual environmental contamination, environmental samples were tested, and results of the biosensor assay were compared to data obtained from chemical methods. Environmental groundwater and soil samples were collected from contaminated sites that are known to possess petroleum product contamination in the Lin-Yuan Industrial Park, Kaohsiung, Taiwan in December 2005. The bioavailable fraction of the BTEX was determined from groundwater and water extracts of soil using the E. coli DH5 $\alpha$ (pTOLLUX)-based luminescence and $E$. coli DH5 $\alpha$ (pTOLGFP)-based fluorescence biosensors. A standard curve was generated with known concentrations of toluene, and the resulting equations $\left(r^{2}=0.9412\right.$ and $r^{2}=0.9498$, for luminescence and fluorescence biosensors, respectively) were used to calculate the toluene equivalent concentrations of the environmental samples. By calculating the contaminant concentrations from the standard curve and taking the dilution factor of the assay into account (see Section 2), the final concentrations of contaminants in the samples are shown in Table 1. Because we could not differentiate between possible effectors in the environmental samples, the data were expressed as toluene equivalents. Additionally, possible inhibitory effects that might be caused by chemicals other than the effector compounds in the water sample were also assessed by spiking the sample with a known concentration of toluene $\left(500 \mu \mathrm{mol} \mathrm{L}^{-1}\right)$. Subsequently, the total SLI or SFI was measured and then compared to that of a positive control containing the same concentration in deionized water. No inhibitory effect was detected. Therefore, it is unlikely that non-effector compounds in the environmental water samples interfered with the luminescence or fluorescence values.

Table 1 compares the results of groundwater and soil sample testing conducted by the chemical analytical method (GCMS) with the biosensor assays. The same batches of groundwater and soil samples were analyzed by the biosensor assay and the chemical analytical method. No detectable toluene was obtained by the GC-MS analysis in either the groundwater or soil water-extracted sample, while the results from the biosensor assays showed $362 \pm 19$ and $283 \pm 27 \mu \mathrm{mol} \mathrm{L}^{-1}$ toluene equivalent in the groundwater sample for the luminescence biosensor and fluorescence biosensor, respectively, and $168 \pm 63$ and $157 \pm 13 \mu \mathrm{mol} \mathrm{L}^{-1}$ in water-extract of the soil sample for the luminescence biosensor and fluorescence biosensor, respectively. It should be noted that toluene, xylene, naphthalene, and catechol were not detected in the environmental samples analyzed by GC-MS analysis, whereas several aromatic compounds were detected by GC-MS analysis including ethylbenzene $\left(178.5 \mu \mathrm{mol} \mathrm{L}^{-1}\right)$ and benzaldehyde $\left(<50 \mu \mathrm{mol} \mathrm{L}^{-1}\right)$ for the groundwater sample and 
Table 1

Comparison of analytical methods for detecting toluene equivalent concentrations in environmental groundwater and soil samples

\begin{tabular}{|c|c|c|c|}
\hline Detection method & Sample type & Detected compound & Estimated toluene equivalent concentration $\left(\mu \mathrm{mol} \mathrm{L}{ }^{-1}\right)$ \\
\hline \multirow[t]{2}{*}{ GC-MS } & Groundwater & Toluene equivalent & $-^{\mathrm{a}}$ \\
\hline & Soil (extracted with water) & Toluene equivalent & $-{ }^{\mathrm{b}}$ \\
\hline \multirow[t]{2}{*}{ Bacterial biosensor (pTOLLUX) } & Groundwater & Toluene equivalent & $362 \pm 19^{c}$ \\
\hline & Soil (extracted with water) & Toluene equivalent & $168 \pm 6^{\mathrm{c}}$ \\
\hline \multirow[t]{2}{*}{ Bacterial biosensor (pTOLGFP) } & Groundwater & Toluene equivalent & $283 \pm 27^{\mathrm{d}}$ \\
\hline & Soil (extracted with water) & Toluene equivalent & $157 \pm 13^{\mathrm{d}}$ \\
\hline
\end{tabular}

a - , toluene was not detectable but ethylbenzene $\left(178.5 \mu \mathrm{mol} \mathrm{L}{ }^{-1}\right)$ and benzaldehyde $\left(<50 \mu \mathrm{mol} \mathrm{L}^{-1}\right)$ were detected.

b - , toluene was not detectable but ethylbenzene $\left(160.4 \mu \mathrm{mol} \mathrm{L}^{-1}\right)$, benzaldehyde $\left(<50 \mu \mathrm{mol} \mathrm{L}{ }^{-1}\right)$, and phenol $(<50 \mu \mathrm{mol} \mathrm{L}-1)$ were detected.

c Values were calculated by extrapolating the luminescence emission data to the toluene-derived standard curve and are expressed as toluene equivalents.

d Values were calculated by extrapolating the green fluorescence emission data to the toluene-derived standard curve and are expressed as toluene equivalents.

ethylbenzene $\left(160.4 \mu \mathrm{mol} \mathrm{L}^{-1}\right)$, benzaldehyde $\left(<50 \mu \mathrm{mol} \mathrm{L}^{-1}\right)$, and phenol $\left(<50 \mu \mathrm{mol} \mathrm{L}^{-1}\right)$ for the soil water-extracted sample. Since ethylbenzene, benzaldehyde, and phenol are the effectors for toluene bacterial biosensors, it is possible that the induction seen in the bacterial biosensor assays for the groundwater sample was mainly contributed by ethylbenzene and partially by benzaldehyde. For the soil sample, the induction seen in the bacterial biosensor assays was possibly mainly contributed by ethylbenzene and partially by benzaldehyde and phenol present in the soil sample.

\section{Discussion}

In this study, we describe the construction, characterization, and comparison of fluorescence and bioluminescence bacterial biosensors for the measurement of bioavailable toluene and related compounds, and we address the feasibility of choosing a reporter for pollutant biosensor systems. Several bacterial biosensors for toluene and related compounds have been described (Applegate et al., 1998; Willardson et al., 1998; Stiner and Halverson, 2002; Casavant et al., 2003; Paitan et al., 2004; Kim et al., 2005), but the question of the suitability of reporter systems has seldom been critically examined and compared. Herein, we attempted to compare a green fluorescent reporter protein-based and a bacterial luminescent enzymatic reporterbased toluene biosensor. We studied the performance of the $g f p$ and luxCDABE reporter genes in identical constructs which made direct comparison possible. The recombinant constructs, designated pTOLGFP and pTOLLUX, were based on expressions of the $g f p$ and $l u x C D A B E$ genes, respectively, under the control of the Pu promoter and the $x y l R$ gene of the $P$. putida TOL plasmid. Cells harboring this construct are capable of producing detectable signals upon exposure to toluene and related compounds with high sensitivity.

In addition to the genetic constructs, several factors might also have affected the sensitivities and induction coefficients of these biosensors. These include the host strains, incubation times, medium compositions, growth phases of the harvested bacteria, and amounts of bacteria per measurement (Tauriainen et al., 1997; Hansen and Sørensen, 2000). It may have been possible to improve the performances of the biosensors by individually optimizing the factors that affect the bacterial biosensors for each reporter gene. For comparison purposes, however, both biosensor plasmids were produced using the same bacterial strain of E. coli DH5 $\alpha$, and cultivation and measurements were performed identically for both the luminescence and fluorescence bacterial biosensors.

It appears that the selectivities of the effectors for both luminescence and fluorescence bacterial biosensors were similar (Fig. 2), and the response to each compound slightly differed from those observed in other reports (Abril et al., 1989; Willardson et al., 1998; Stiner and Halverson, 2002; Kim et al., 2005). Although naphthalene and benzaldehyde were not effectors for previously reported bacterial biosensors (Abril et al., 1989; Stiner and Halverson, 2002), our results showed that both luminescence and fluorescence bacterial biosensors were strongly induced by naphthalene and slightly induced by benzaldehyde (Fig. 2). The reason for the difference can be ascribed to the different genetic constructs, cultivation, and measurement protocols used.

It appears that induction of the pTOLLUX construct was much more sensitive than induction of the pTOLGFP construct (Figs. 2-4). Our results indicated that the bacterial luminescence biosensor has two major advantages for detecting toluene and related compounds: a faster response time and higher shortterm sensitivities (Figs. 3 and 4). Both advantages result from the catalytic nature of the luxCDABE enzymatic reporter, which allows a relatively small number of reporter molecules to produce a sufficiently strong signal. In contrast, the bacterial fluorescence biosensor exhibited a slower response to the effector, which means that significant induction was seen only after a longer incubation period. This might have been due to the slow folding of the green fluorescent proteins. The main advantage of the bacterial fluorescence biosensor is the stability of the GFP. This is particularly useful for the detection of highly toxic environmental samples. Once induced by an effector, the green fluorescence keeps accumulating and may be detected for many hours (Fig. 3A) even after cell death. In contrast, bacterial luminescence activity is considerably short-lived. In the pTOLLUX construct, the luxCDABE gene was used as the reporter gene: lux $A B$ codes for the luciferase that catalyzes reactions involving the oxidation of a reduced riboflavin phosphate and a long-chain fatty aldehyde, while luxCDE encodes enzymes that are responsible for the synthesis of the long-chain aldehyde substrate that is required for the bioluminescence reaction. Therefore, the combined half-life of the overall activity is short for the bacterial 
luminescence biosensor as shown in Fig. 3B. Additionally, to demonstrate the utility of the toluene biosensors in measuring actual environmental contamination, petroleum product-contaminated groundwater and soil samples were assayed by toluene luminescence and fluorescence bacterial biosensors, and results were compared to the data from the GC-MS chemical method. Environmental sample concentrations of toluene estimated by the luminescence and fluorescence bacterial biosensors compared closely to each other.

\section{Conclusions}

In summary, for determining the bioavailable portion of the BTEX in groundwater and soil samples, biosensor bacteria are likely to provide a more-realistic view, providing critical data that can be useful in risk assessment. This study demonstrates that toluene bacterial biosensors represent a simple, fast, inexpensive, and less-laborious alternative to conventional HPLC and GC-MS methods of BTEX measurement. The greatest advantage of this type of toluene bacterial biosensor may be the ease with which it can be applied to field testing and used for screening both the presence and bioavailable fractions of BTEX in the environment. This is particularly useful when a large number of environmental samples need to be analyzed. However, the choice of a reporter gene for the analysis of BTEX and related compounds has to be case-specific. Based on our results, the bioluminescence biosensor was more suitable for rapid and sensitive detection of toluene and related compounds, while the green fluorescence biosensor was more applicable for long-term exposure and cumulative signal detection.

\section{Acknowledgements}

This work was financially supported by the Taiwan National Science Council (grant nos. NSC93-2211-E-002-014, 92-2211E-002-054, and 91-2211-E-002-096). We thank Dr. Andrew Whiteley, Centre for Ecology and Hydrology, Oxford, UK, for technical advice on the bacterial luminescence assay.

\section{References}

Abril, M.A., Michan, C., Timmis, K.N., Ramos, J.L., 1989. Regulator and enzyme specificities of the TOL plasmid-encoded upper pathway for degradation of aromatic hydrocarbons and expansion of the substrate range of the pathway. J. Bacteriol. 171, 6782-6790.

Applegate, B.M., Kehrmeyer, S.R., Sayler, G.S., 1998. A chromosomally based tod-luxCDABE whole-cell reporter for benzene, toluene, ethybenzene, and xylene (BTEX) sensing. Appl. Environ. Microbiol. 64, 27302735.

Burlage, R.S., Hooper, S.W., Sayler, G.S., 1989. The TOL (pWW0) catabolic plasmid. Appl. Environ. Microbiol. 55, 1323-1328.

Casavant, N.C., Thompson, D., Beattie, G.A., Phillips, G.J., Halverson, L.J., 2003. Use of a site-specific recombination-based biosensor for detecting bioavailable toluene and related compounds on roots. Environ. Microbiol. $5,238-249$.

Dollard, M.A., Billard, P., 2003. Whole-cell bacterial sensors for the monitoring of phosphate bioavailability. J. Microbiol. Methods 55, 221-229.

Flynn, H.C., Meharg, A.A., Bowyer, P.K., Paton, G.I., 2003. Antimony bioavailability in mine soils. Environ. Pollut. 124, 93-100.

Hakkila, K., Maksimow, M., Karp, M., Virta, M., 2002. Reporter genes lucFF, luxCDABE, gfp, and dsred have different characteristics in whole-cell bacterial sensors. Anal. Biochem. 301, 235-242.

Hansen, L.H., Sørensen, S.J., 2000. Versatile biosensor vectors for detection and quantification of mercury. FEMS Microbiol. Lett. 193, 123-127.

Kim, M.N., Park, H.K., Lim, W.K., Shin, H.J., 2005. Construction and comparison of Escherichia coli whole-cell biosensors capable of detecting aromatic compounds. J. Microbiol. Methods 60, 235-245.

Layton, A.C., Lajoie, C.A., Easter, J.P., Jernigan, R., Sanseverino, J., Sayler, G.S., 1994. Molecular diagnostics and chemical analysis for assessing biodegradation of polychlorinated biphenyls in contaminated soils. J. Ind. Microbiol. 13, 392-401.

Miller, W.G., Leveau, J.H., Lindow, S.E., 2000. Improved gfp and inaZ broadhost-range promoter-probe vectors. Mol. Plant Microbe Interact. 13, $1243-1250$.

Paitan, Y., Biran, I., Shechter, N., Biran, D., Rishpon, J., Ron, E.Z., 2004. Monitoring aromatic hydrocarbons by whole cell electrochemical biosensors. Anal. Biochem. 335, 175-183.

Rogowsky, P.M., Close, T.J., Chimera, J.A., Shaw, J.J., Kado, C.I., 1987. Regulation of the vir genes of Agrobacterium tumefaciens plasmid pTiC58. J. Bacteriol. 169, 5101-5112.

Sagi, E., Hever, N., Rosen, R., Bartolome, A.J., Premkumar, J.R., Ulber, R., Lev, O., Scheper, T., Belkin, S., 2003. Fluorescence and bioluminescence reporter functions in genetically modified bacterial sensor strains. Sens. Actuators. B Chem. 90, 2-8.

Stiner, L., Halverson, L.J., 2002. Development and characterization of a green fluorescent protein-based bacterial biosensor for bioavailable toluene and related compounds. Appl. Environ. Microbiol. 68, 1962-1971.

Tauriainen, S., Karp, M., Chang, W., Virta, M., 1997. Recombinant luminescent bacteria for measuring bioavailable arsenite and antimonite. Appl. Environ. Microbiol. 63, 4456-4461.

Willardson, B.M., Wilkins, J.F., Rand, T.A., Schupp, J.M., Hill, K.K., Keim, P., Jackson, P.J., 1998. Development and testing of a bacterial biosensor for toluene-based environmental contaminants. Appl. Environ. Microbiol. 64, 1006-1012. 